\title{
Divisão internacional do conhecimento e o declínio das ciências humanas: o cenário das instituições privadas de educação superior na Região Nordeste do Brasil
}

\author{
Alisson Slider do Nascimento de Paula' \\ Frederico Jorge Ferreira Costa' \\ Kátia Regina Rodrigues Lima"l

RESUMO

O presente artigo objetivou analisar o cenário da oferta de cursos de graduação por área de formação profissional das instituições privadas de educação superior na Região Nordeste do Brasil e sua correlação com as condicionalidades da economia do conhecimento. Para se obter uma ideia clara acerca do universo quantitativo da oferta de cursos, utilizamos a base de dados relativa às instituições de educação superior e aos cursos de graduação e-MEC. Constatou-se que a educação superior brasileira vivencia uma proeminência do setor privado, bem como a predominância da oferta de cursos superiores focados em áreas rentáveis para a acumulação capitalista e a consequente subalternização das ciências humanas decorrente da submissão da educação ao economicismo vinculado ao movimento da globalização e à emergência da economia do conhecimento.

PALAVRAS-CHAVE

economia do conhecimento; educação superior privada; ciências humanas. 
INTERNATIONAL DIVISION OF KNOWLEDGE

AND THE DECLINE OF HUMAN SCIENCES: THE

SCENARIO OF PRIVATE INSTITUTIONS OF HIGHER

EDUCATION IN THE NORTHEAST OF BRAZIL

\begin{abstract}
This article aims to analyze the scenario of the offer of undergraduate courses by professional training area of private higher education institutions in the Northeast region of Brazil and its correlation with the conditions of the knowledge economy. In order to obtain a clear idea about the quantitative universe of the courses offered, we used the database on higher education institutions and e-MEC undergraduate courses. We found that Brazilian higher education experiences a prominence of the private sector, as well as the predominance of the offer of higher education courses centered on profitable areas for capitalist accumulation, and the consequent subalternization of human sciences due to the submission of education to economism linked to the globalization movement and the emergence of the knowledge economy.
\end{abstract}

KEYWORDS

knowledge economy; private higher education; human sciences.

\title{
DIVISIÓN INTERNACIONAL DEL CONOCIMIENTO Y EL DECLINIO DE LAS CIENCIAS HUMANAS: EL ESCENARIO DE LAS INSTITUCIONES PRIVADAS DE EDUCACIÓN SUPERIOR EN LA REGIÓN NORDESTE DE BRASIL
}

\section{RESUMEN}

El presente artículo tiene como objetivo analizar el escenario de la oferta de cursos de graduación por área de formación profesional de las instituciones privadas de educación superior en la región Nordeste de Brasil y su correlación con las condicionalidades de la economía del conocimiento. Para obtener una idea clara sobre el universo cuantitativo de la oferta de cursos, utilizamos la base de datos relativa a las instituciones de educación superior y cursos de graduación e-MEC. Constatamos que la educación superior brasileña vive una prominencia del sector privado, así como la predominancia de la oferta de cursos superiores centrados en áreas rentables para la acumulación capitalista, y la consiguiente subalternización de las ciencias humanas derivada de la sumisión de la educación al economicismo vinculado al movimiento de la globalización y la emergencia de la economía del conocimiento.

PALABRAS CLAVE:

economía del conocimiento; educación superior privada; ciencias humanas. 


\section{INTRODUÇÃO}

A economia global vivencia metamorfoses oriundas das crises do sistema de capital desdobradas sobretudo da década de $1970 \mathrm{em}$ diante. Com as mudanças sofridas pelo modo de acumulação capitalista, surgiu uma concepção articulada à ideia de um tipo de capitalismo cognitivo, isto é, uma economia baseada no conhecimento. Para tanto, diversas condicionalidades vinculadas ao fenômeno da globalização foram ao encontro dessa racionalidade, direcionando mudanças para instituições republicanas, principalmente nos Estados nacionais periféricos e em suas instituições de ensino superior (IES).

Com o fortalecimento do mercado internacional, intensificou-se a processualidade da Divisão Internacional do Trabalho (DIT) e implicações para as nações centrais e periféricas. Contudo, nesse mesmo processo, a ascensão da economia do conhecimento partiu da lógica da divisão internacional da produção do conbecimento. Desse modo, foi dado relevo para áreas de formação profissional vinculadas às ciências exatas, biológicas e de saúde, que vamos classificar como ciências duras, em detrimento das ciências humanas.

Partindo desse pressuposto, o presente artigo objetivou analisar o cenário da oferta de cursos de graduação por área de formação profissional - aqui divididas em quatro áreas: tecnológica, saúde, engenharia e ciências humanas ${ }^{1}-$ das Instituições Privadas de Ensino Superior (IPES) da Região Nordeste do Brasil e constituir um diagnóstico desse cenário. As IPES avaliadas foram universidades e centros universitários privados com e sem fins lucrativos ${ }^{2}$.

O Nordeste foi selecionado por equivaler, de acordo com a Ser Educacional (2018), a um campo promissor para o desenvolvimento do mercado educacional no Brasil, visto que o número de ingressantes nessa região na esfera privada da educação superior foi de 247.053 em 2016, ocupando o segundo lugar de região com o maior número de ingressantes, ficando atrás apenas do Sudeste (Inep, 2016). É lícito ressaltar que delimitamos nossa análise às IPES por buscarem atender às demandas do mercado. Assim, com a autonomia para abertura e fechamento de cursos, é exequível identificar a tendência subjacente que condiciona a predominância de específicas áreas sobre as demais. Destarte, a análise do Nordeste faz-se essencial para se obter um diagnóstico do panorama da oferta de cursos de ciências humanas, bem como das demais áreas ofertadas nas IPES dessa região.

A fim de atingir o objetivo delimitado, realizamos uma pesquisa qualitativa, que, a rigor, pretende explicar a essência do objeto. Para Minayo (2001, p. 21), a

1 O Instituto Nacional de Estudos e Pesquisas Educacionais Anísio Teixeira (Inep) classifica as áreas gerais de cursos: ciências sociais, negócios e direitos; educação; saúde e bem-estar social; engenharia, produção e construção; ciências, matemática e computação; agricultura e veterinária; e humanidades e artes. Todavia, na presente pesquisa não utilizamos essa classificação em função de alguns cursos, embora pertençam a uma área, se vincularem à outra, o que é algo totalmente aceitável, como, por exemplo, a área de educação, a qual pode estar vinculada às ciências sociais e humanas. Nesse sentido, fazemos uso de quatro áreas genéricas: tecnológica, saúde, engenharia e ciências humanas.

2 Optamos por analisar apenas as universidades e os centros universitários privados, por corresponderem à IPES que possuem autonomia para a criação e oferta de seus cursos de graduação. 
pesquisa qualitativa "trabalha com o universo de significados, motivos, aspirações, crenças, valores e atitudes, o que corresponde a um espaço mais profundo das relações, dos processos e dos fenômenos que não podem ser reduzidos à operacionalização de variáveis". Optou-se pelo método da análise documental, que recorre a "fontes mais diversificadas e dispersas, sem tratamento analítico, tais como: tabelas estatísticas, jornais, revistas, relatórios, documentos oficiais, cartas, filmes, fotografias, pinturas, tapeçarias, relatórios de empresas, vídeos de programas de televisão, etc." (Fonseca, 2002, p. 32). Em acréscimo, Lüdke e André (1986, p. 40) asseveram que a primeira etapa para a análise documental consiste na "caracterização do tipo de documento que será usado ou selecionado". Na referida pesquisa, os documentos selecionados foram os oficiais do Ministério da Educação (MEC) acerca das IPES da região em tela.

Para obtenção dos dados, fizemos um levantamento no sítio da plataforma e-MEC, que funciona como base de Cadastro Nacional de Cursos e Instituições de Educação Superior no Brasil ${ }^{3}$. A pesquisa deu-se por meio dos critérios: "consulta avançada", apenas "cursos de graduação", "estados da Região Nordeste", categoria administrativa "com e sem fins lucrativos", organização acadêmica "centro universitário" e "universidade", e tipo de credenciamento "presencial".

Após a coleta de dados, partimos para sua análise, em que foi empregada a análise de conteúdo, que, para Moraes (1999, p. 9), constitui uma técnica de pesquisa usada para descrever e interpretar o conteúdo de todos os tipos de documentos e textos, além de conduzir a "descrições sistemáticas, qualitativas ou quantitativas, ajuda a reinterpretar as mensagens e a atingir uma compreensão de seus significados num nível que vai além de uma leitura comum”. Por fim, analisamos e comparamos os dados entre os estados nordestinos gerando um diagnóstico acerca da oferta dos cursos de graduação, enfatizando o cenário dos cursos de ciências humanas nas IPES.

Nesse sentido, inicialmente avaliamos a concepção da economia do conhecimento como decorrente do sistema sociometabólico do capital, sua proeminência financeira e suas condicionalidades para as nações subdesenvolvidas ${ }^{4}$. Em seguida, partimos para a análise dos dados coletados sobre os cursos ofertados pelas IPES

3 O Cadastro e-MEC é regulamentado pela Portaria Normativa no 21, de 21 de dezembro de 2017. Esse sistema foi criado objetivando realizar a tramitação eletrônica dos processos de regulação na educação superior. As IES, por meio do suporte on-line, podem fazer credenciamento e recredenciamento, buscar autorização, reconhecimento e renovação de cursos. A plataforma está em operação desde janeiro de 2007.

4 A sociedade do conhecimento é considerada, para Duarte (2008), uma ideologia produzida pelo sistema capitalista, "um fenômeno no campo da reprodução ideológica do capitalismo" (Duarte, 2008, p. 13). Em acréscimo, Duarte (2008), ao indagar sobre a função ideológica efetivada pela crença na sociedade conhecimento, compreende que "seria justamente a de enfraquecer as críticas radicais ao capitalismo e enfraquecer a luta por uma revolução que leve a uma superação radical do capitalismo, gerando a crença de que essa luta teria sido superada pela preocupação com outras questões 'mais atuais', tais como a questão da ética na política e na vida cotidiana pela defesa dos direitos do cidadão e do consumidor, pela consciência ecológica, pelo respeito às diferenças sexuais, étnicas ou de qualquer outra natureza" (Duarte, 2008, p. 14). 
do Nordeste brasileiro. Ademais, buscamos desvelar o duplo movimento da mercadorização da educação decorrente da economia baseada no conhecimento e a consequente subalternização das ciências humanas.

\section{A GLOBALIZAÇÃO, A ASCENSÃO DA ECONOMIA DO CONHECIMENTO E A PROEMINÊNCIA DAS AGÊNCIAS INTERNACIONAIS}

A política global efetiva-se em uma dimensão espaçotemporal em que o globo está dividido entre países centrais e periféricos, bem como constituído de medidas que contribuem para a acumulação capitalista dos setores hegemônicos em detrimento dos subalternos. A lógica planetária não é mais apenas um conjunto de nações, Estados nacionais engajados em suas relações interdependentes em que sobressaem temas referentes ao colonialismo. Nações e indivíduos foram, de acordo com Ianni (1997, p. 13-14) "subsumidos, real ou formalmente, pela sociedade global, pelas configurações e movimentos da globalização".

O fenômeno da globalização oriunda dos processos da expansão global do modo de produção capitalista que se deu nesse sentido na década de 1970 em diante, em função da queda da taxa de lucro do setor manufatureiro. No início dos anos 1990, com a queda do muro de Berlim e a consequente incorporação da Rússia e do bloco oriental ao sistema de capital, possibilitou-se, dessa forma, a expansão capitalista em escala planetária. Todavia, consoante Rikowski (2017), no período entre 2007 e 2008 eclodiu a crise de subprime desinente da derrocada do Índice Dow Jones ${ }^{5}$, estimulada pelos empréstimos hipotecários de alto risco, decorrendo, assim, na dissolução de diversos bancos e engendrando severas implicações às bolsas de valores pelo globo.

Com efeito, a crise do sistema econômico agravou-se em consequência de um duplo movimento:

- por conta do deslocamento da força de trabalho para fora dos setores manufatureiros, de acordo com Srnicek e Williams (2015);

- em razão desse primeiro movimento, descrito no tópico anterior, não seria factível a criação de capital necessário para manter, conforme Kurz (2016), o desenvolvimento metabólico do capital. Nessa acepção, Rikowski (2017) compreende que o capital global vivencia uma penosa situação. Para tanto, o financiamento público estatal da educação despertou atenção dos setores empresariais. Segundo Verger, Steiner-Khamsi e Lubienski (2017, p. 325), "the value of the world education market was $\$ 4.9$ trillion (US dollars) in 2015" ["o valor do mercado educacional mundial era de $\$ 4,9$ trilhões (em dólares) em 2015”]. Portanto, o controle da educação por empresas do setor financeiro não é nada inesperado ou fortuito.

5 O Índice Dow Jones é um indicador do mercado estadunidense de grande relevo que corresponde ao valor de 30 grandes ações industriais, as quais possuem ações na Bolsa de Valores de Nova York. 
O fenômeno da globalização aprofunda a lógica da DIT. Assim, os Estados nacionais ocupam posições diferenciadas concernentes às estruturas e aos impactos da globalização. Lingard e Rizvi (2000) captaram esse movimento assimétrico no desenvolvimento das nações. Para os autores, "a globalização invade os contextos locais mais não os destrói; pelo contrário, novas formas de identidade e auto expressão cultural local são, por consequência, conectadas ao processo de globalização" (Lingard e Rizvi, 2000, p. 2.100).

Não obstante, o sentido do conceito de globalização $0^{6}$ aqui em nada se diferencia da noção compreendida de que os Estados nacionais do centro orientam os rumos dos Estados periféricos da economia global. Destarte, Sguissardi explicita esse panorama:

Pela descentralização de grandes empresas, do ramo industrial, por exemplo, cujas unidades se multiplicam e se espalham por diversas regiões e países, com menores custos e maiores vantagens quanto à força de trabalho (mais barata), matéria prima, legislação trabalhista, universidades que pesquisam e formam mão de obra especializada para empresas com subsídio estatal, etc. A força econômica dessas empresas sobrepor-se-ia à de muitos Estados nacionais e suas instituições republicanas, como a universidade e instituições de pesquisa. (Sguissardi, 2015, p. 95)

No interior dessa racionalidade, diversas são as perspectivas engendradas e que reverberam severas implicações no modus operandi das instituições republicanas, mormente as educacionais. Entre elas, damos destaque para aquilo que alguns autores (Afonso, 2015; Rhoades e Slaughter, 2009; Santiago e Carvalho, 2011; Olssen e Peters, 2005; Jarvis, 2000) denominam de economia do conhecimento. O conceito de economia do conhecimento, para Afonso (2015), contempla, em linhas gerais, as noções de sociedade do conhecimento, aprendizagem ao longo da vida, sociedade cognitiva, sociedade da informação, entre outras, que tematizam elementos de uma mesma sociedade, além de serem evocadas quando necessárias para respaldar e legitimar a aprovação de políticas e a "definição de orientações económicas e empresariais ou a indução de práticas sociais e educacionais direcionadas para atender o que se consideram ser, em termos genéricos, as [...] exigências do capitalismo" (Afonso, 2015, p. 270).

Com a redução da taxa de lucro do setor manufatureiro e a ênfase dada ao setor educacional, sobretudo na formação profissional, decorrente da hegemonia financeira, a economia do conhecimento tornou-se um nicho mercadológico por compreender a aprendizagem como um elemento altamente rentável (Afonso, 2015). A despeito de a Organização das Nações Unidas para a Educação, a Ciência e a

6 Não obstante a coerência do conceito de mundialização do capital proposto por Chesnais (1996) para caracterizar os padrões de acumulação do capital mundial, Ianni (1997) abrange essa compreensão conforme uma das teorias da globalização. Nessa acepção, optamos pela utilização dessa teoria, mais abrangente, portanto, atribuindo mais conteúdo à forma da globalização. 
Cultura em documento intitulado Rumo às sociedades do conhecimento (Unesco, 2017) denotar o caráter humanístico da sociedade do conhecimento, sobressaem, nessa situação, a supremacia econômica e a competitividade obsessiva. No limite, quanto mais rentável for para o Estado ou para a empresa a economia do conhecimento, por conseguinte essa economia terá maior importância.

Esse panorama ganhou novos elementos com o movimento de hierarquização das áreas do conhecimento. Isso porque as ciências que correspondem a níveis satisfatórios para produção de inovação para a vida industrial, para Bell (2001), são a engenharia e a economia. Além disso, Afonso (2015) destaca o neocolonialismo efetivado na educação superior periférica, por meio de sua consequente comodificaçãa ${ }^{7}$ e dependência dos conhecimentos e orientações advindos das nações centrais. É lícito ressaltar, também, a ênfase dada aos cursos de tecnologia em detrimento dos cursos de ciências humanas. Na própria visão do Banco Mundial (BM), as ciências físicas e da engenharia ganham relevo pela capacidade de promover um suposto avanço nacional.

A capacidade de uma nação de criar novos conhecimento e tecnologia está intimamente ligada à habilitação técnica e avançada e a um sistema de ensino superior especialmente forte em ciência, engenharia e aplicação tecnológica. O Brasil enfatizou as ciências humanas e sociais, em detrimentos das ciências físicas e da engenharia. (Banco Mundial, 2008, p. 33)

Nessa acepção, além dos cursos de engenharia e de tecnologia, deu-se ênfase aos cursos da área da saúde, o que corresponde aos interesses dos setores empresariais na exploração de áreas tidas como promissoras, inspiradas pelas alterações nos postos de emprego de nível superior. Essa lógica, não obstante ser global, possui fortes particularidades no contexto brasileiro. De acordo com Rodrigues (2007), a categoria mercadoria-educação não se limita apenas ao setor dos donos das IPES, todavia aos insumos para os setores empresariais, isto é, aos cursos que encaminharão a formação dos profissionais para atender à oferta do mercado. Portanto, é nesse contexto que se metamorfoseia a lógica da oferta de cursos na educação superior brasileira.

\section{O PANORAMA DAS IPES NO NORDESTE BRASILEIRO}

O setor financeiro criou uma complexa teia de processos de privatização da educação superior. No Brasil esse processo está alinhado às orientações das agências internacionais, bem como à sua particularidade capitalista, ou seja, de caráter

7 O conceito de comodificação utilizado em nossa pesquisa se remete ao processo de mercadorização de um serviço social. Contudo, em função da particularidade capitalista brasileira, a lógica dos commodities caracteriza-se no âmbito das matérias-primas, isto é, com baixo valor agregado e pouco refinamento. Nesse sentido, os cursos de formação profissional não fogem desse escopo, por isso a ênfase dada à formação técnica atrelada às ciências duras. 
dependente. A particularidade da periferia capitalista reverbera na subalternização do Estado nacional às nações centrais, podendo ser classificado, no assunto em tela, como imperialismo acadêmico ou neocolonialismo acadêmico. De todo modo, com o movimento da transnacionalização financeira, inserção de fundos de investimento, fundos de pensão, bancos e outros entes privados e sua parceria com Estado, a educação sofreu um processo de comodificação ${ }^{8}$.

A partir da década de 1980, as reformas que os Estados nacionais empreenderam buscaram a retomada da expansão capitalista, mormente sua rentabilidade financeira, visto que a eclosão da crise da dívida afetou diretamente os países latino-americanos (Barreto e Leher, 2008). Em acréscimo, esse processo implicou maior concentração de riqueza, retração do papel do Estado na garantia de direitos e sua consequente maior vinculação com o mercado. Com a maior conexão da esfera público-estatal com o mercado, diversas políticas foram criadas para dilacerar as fronteiras entre o público e o privado, contudo essas políticas não surgiram do nada, sem nenhum tipo de inspiração. Tais políticas estiveram situadas fundamentadas nas orientações do capital financeiro, calcadas na lógica da globalização. Ball (2001) de modo magistral explicita a lógica da criação de políticas com base no fenômeno da globalização.

A criação das políticas nacionais é, inevitavelmente, um processo de "bricolagem”; um constante processo de empréstimo e cópia de fragmentos e partes de ideias de outros contextos, de uso e melhoria das abordagens locais já tentadas e testadas, de teorias canibalizadoras, de investigação, de adoção de tendências e modas e, por vezes, de investimento em tudo aquilo que possa vir a funcionar. A maior parte das políticas são frágeis, produtos de acordos, algo que pode ou não funcionar; elas são retrabalhadas, aperfeiçoadas, ensaiadas, crivadas de nuances e moduladas através de complexos processos de influências, produção e disseminação de textos e, em última análise, recriadas nos contextos da prática. [...] Estes campos constituem-se de forma diferente em distintas sociedades. Em resumo, as políticas nacionais necessitam ser compreendidas como o produto de um nexo de influências e interdependências que resultam numa "interconexão, multiplexidade, e hibridização" [...], isto é, "a combinação de lógicas globais, distantes e locais". (Ball, 2001 p. 102)

8 Com o movimento incessante de abertura e fechamento de instituições e cursos, além do movimento de aquisição e fusões, joint venture, das IPES por grandes holdings educacionais, os cursos de graduação situam-se na disputa pelo lucro, e a qualidade irradiada pelo Sistema Nacional de Avaliação da Educação Superior (Sinaes) corresponde à lógica do gerencialismo (Rothen et al., 2019). Nessas circunstâncias, os cursos de graduação das IPES possuem qualidade contestável quando sua ênfase é dada explicitamente ao ensino, dilacerando as dimensões de pesquisa e extensão. 
Nesse sentido, sob influências de diretrizes globais para as políticas educacionais, uma miríade de políticas foi lançada para fortalecer o setor dos empresários da educação superior. Programas como o Fundo de Financiamento Estudantil (Fies), instituído pela Lei no 10.261/01, alterada pela Lei no 13.530/17; o Programa Universidade para Todos (ProUni), pela Lei no 11.096/05; as parcerias público-privadas, pela Lei no 11.079/04; além do respaldo da Lei no 9.394/96, que estabelece as Diretrizes e Bases da Educação Nacional (LDB), e seus regulamentadores, os Decretos $n^{\circ} 2.207$ e no 2.360 de 1997, que tornam possível a existências de IPES com fins lucrativos, possibilitaram o exponencial crescimento da educação superior privada/mercantil no Brasil.

Com isso, analisamos os dados da oferta de cursos de graduação por área de formação profissional das IPES brasileiras na Região Nordeste, com ênfase nas universidades e nos centros universitários privados com e sem fins lucrativos. A região em tela é marcada por nove estados em que a educação superior se constitui, ainda que de modo mais atrasado que a Região Sudeste ${ }^{9}$, de IES públicas e privadas. Concernente às IPES, o Gráfico 1 traz um panorama quantitativo dessas instituições.

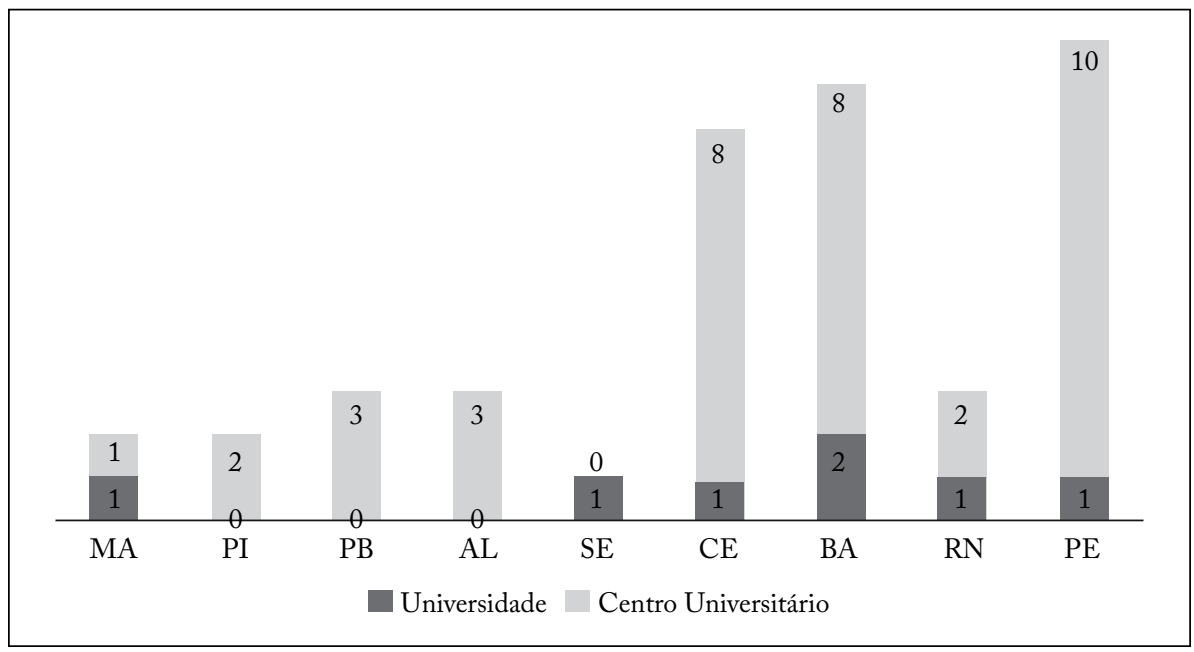

Gráfico 1 - Índice de universidades e centros universitários privados no Nordeste, 2018.

Fonte: e-MEC (2018).

9 De acordo com a estimativa do Instituto Brasileiro de Geografia e Estatística (IBGE, 2017), a Região Nordeste possui 53,59 milhões de habitantes distribuídos em nove estados, ao passo que na Região Sudeste são 86,93 milhões de habitantes em quatro estados. No que diz respeito às matrículas discentes no nível graduação, segundo o censo da educação superior (Inep, 2016), no Nordeste se concentram 1.444.368 matrículas, das quais $546.473(37,83 \%)$ se localizam na pública e $897.895(62,17 \%)$ nas IPES. Na Região Sudeste são 3.020.865 matrículas discentes: 647.413 (21,43\%) são públicas e $2.373 .452(78,57 \%)$ privadas. 
No Nordeste são ao todo 44 o número de universidades e centros universitários privados. No tocante às universidades, são sete $(15,90 \%)$ instituições, ao passo que os centros universitários são um total de $37(84,10 \%)$, representando a maior parte das instituições. Constatamos que no Sergipe só existe uma universidade. Nos estados do Piauí, da Paraíba e de Alagoas só existem centros universitários: no primeiro há dois, e os dois subsequentes possuem três cada um. No Ceará são nove IPES, apenas uma $(11,11 \%)$ universidade e oito $(88,89 \%)$ centros universitários. $\mathrm{Na}$ Bahia são duas (20\%) universidades e oito (80\%) centros universitários. No Rio Grande do Norte, no que tange às universidades, só existe uma (33,33\%), ao passo que são três $(66,67 \%)$ os centros universitários. No Maranhão são duas instituições, uma (50\%) universidade e um (50\%) centro universitário. Por fim, em Pernambuco há apenas uma $(9,09 \%)$ universidade e $10(90,91 \%)$ centros universitários.

No Brasil, das 92 universidades privadas (com e sem fins lucrativos), apenas 7,60\% estão localizadas na Região Nordeste. Acerca dos centros universitários, no Brasil eles são 222, e no Nordeste se encontra apenas $16,6 \%$ da quantidade total. Todavia, o que nos interessa aqui, além de mostrar o crescente número de instituições privadas com autonomia para abrir e fechar cursos de acordo com as oscilações do mercado, é identificar o quantitativo da oferta de cursos por área de formação profissional. Com isso, o Gráfico 2 traz o número de cursos ofertados por universidades privadas.

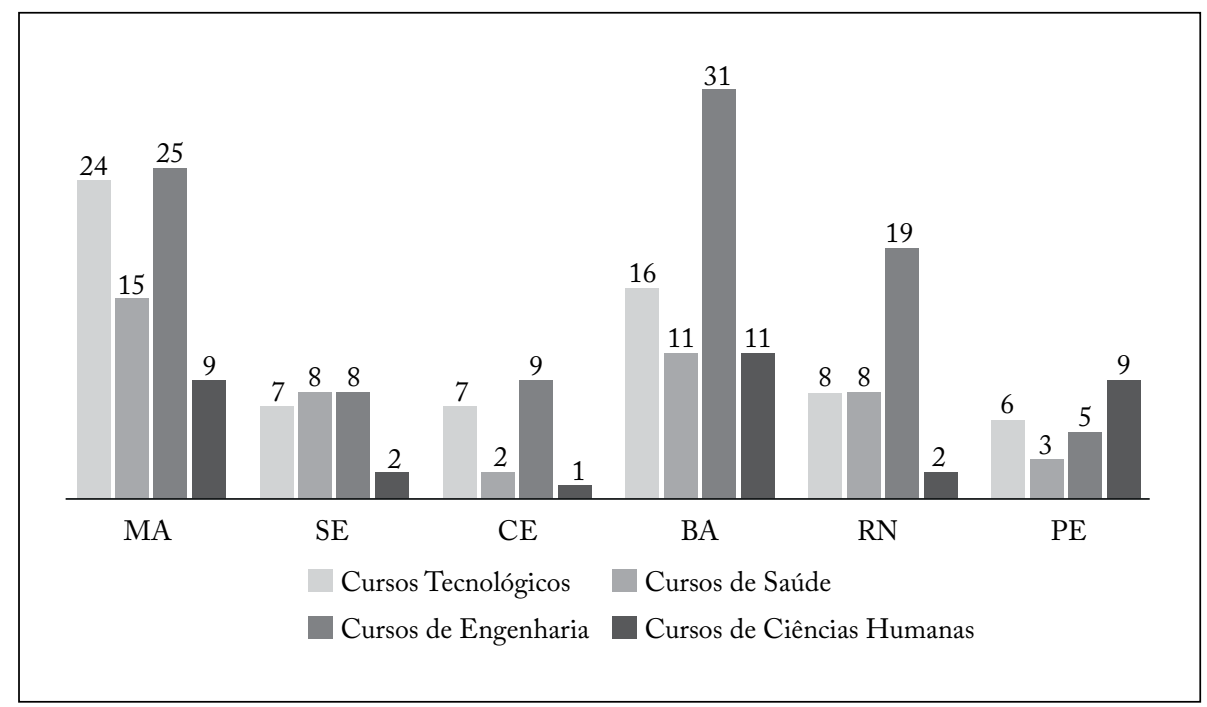

Gráfico 2 - Oferta de cursos por área de formação profissional em universidades privadas, 2018. Fonte: e-MEC (2018).

Nas universidades privadas é nítido até para o mais míope a predominância dos cursos de engenharia, assim como recomendado nas orientações dos organismos internacionais. No levantamento dos cursos por área de formação, na área tecnológica o estado do Maranhão concentra 24 (35,29\%) cursos; no Sergipe, sete (10,29\%); no Ceará, 
concentram-se sete (10,29\%); na Bahia, por sua vez, são 16 (23,52\%); no Rio Grande do Norte são oito (11,76\%); e em Pernambuco, seis $(8,85 \%)$. No que diz respeito à área de engenharia, o Maranhão oferta 25 (25,77\%) cursos; no Sergipe a oferta é de oito (8,28\%); no Ceará, nove (9,27\%); no estado baiano são 31 (31,95\%); o Rio Grande do Norte oferta 19 (19,58\%); e as universidades privadas de Pernambuco ofertam cinco (5,15\%). Na área da saúde, o Maranhão dispõe de 15 (31,91\%) cursos; em Sergipe são oito (17,02\%); no Ceará, a oferta é de apenas dois (4,25\%); no estado da Bahia são 11 (23,40\%); no Rio Grande do Norte, concentram-se oito (17,02\%); e, no limite, Pernambuco oferta apenas três $(6,40 \%)$ cursos. Por fim, na área de ciências humanas, o estado do Maranhão concentra nove (26,47\%) cursos; Sergipe, dois $(5,88 \%)$; no Ceará é um (2,94\%); na Bahia, são 11 (32,36\%); no Rio Grande do Norte, localizam-se, por sua vez, dois (5,88\%); e em Pernambuco são ofertados nove (26,47\%) cursos.

Nas universidades privadas, percebe-se que, não obstante predomine a oferta de cursos de engenharia, as demais áreas de formação estão comparativamente próximas, contudo essas instituições seguem a lógica do modelo de educação superior para os países dependentes. Concernente aos cursos de ciências humanas, o estado da Bahia tem a maior oferta de cursos nessas instituições. Todavia, pelo fato de estarmos tratando apenas de sete instituições universitárias, faz-se preciso analisar a oferta dos 37 centros universitários alocados na Região Nordeste. É o que pretendemos no Gráfico 3.

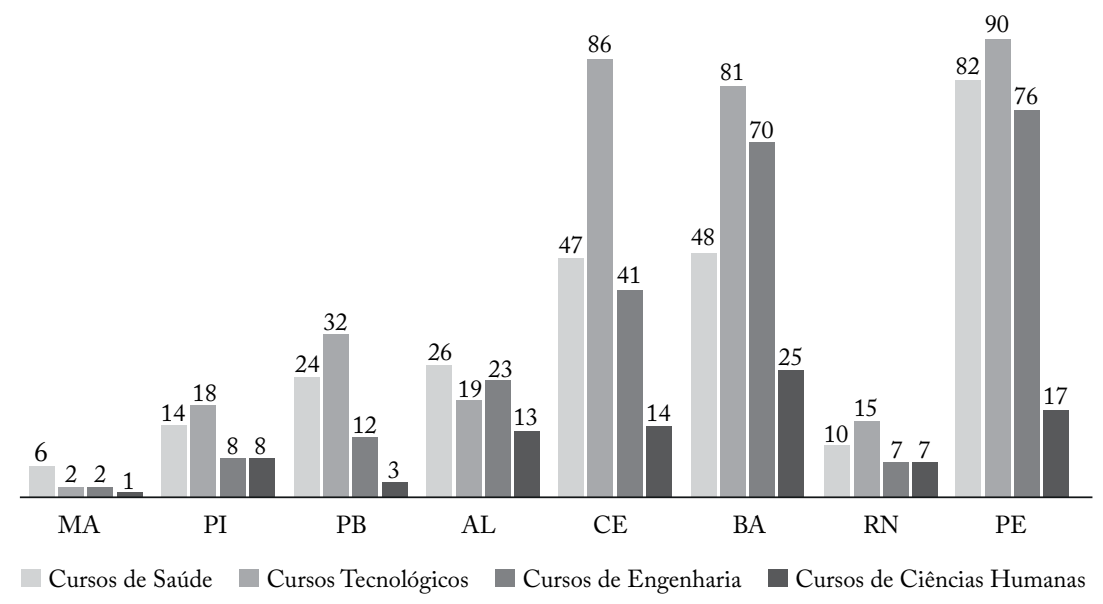

Gráfico 3 - Oferta de cursos por área de formação profissional em centros universitários privados, 2018. Fonte: e-MEC (2018).

Nos centros universitários a oferta por área de formação é mais ampla. Nesse sentido, o universo quantitativo dos cursos expande-se significativamente. $\mathrm{Na}$ área da saúde, constatamos que no estado do Maranhão a oferta é de seis $(2,33 \%)$ cursos; no Piauí são 14 (5,44\%); na Paraíba, concentram-se 24 (9,33\%); em Alagoas a oferta 
é de 26 (10,11\%); no Ceará são 47 (18,28\%); no estado baiano, encontram-se 48 (18,72\%); no Rio Grande do Norte são 10 (3,89\%); e no estado do Pernambuco estão $82(31,90 \%)$ dos cursos de saúde do Nordeste, sendo, assim, a maior concentração da região. Dois cursos da área de engenharia são ofertados no Maranhão (0,82\%); no estado do Piauí é um total de oito (3,34\%); na Paraíba, 12 (5,02\%); no estado alagoano, 23 (9,62\%); no Ceará são 41 (17,15\%); na Bahia, encontram-se 70 (29,28\%); no estado do Rio Grande do Norte estão sete (2,98\%); e em Pernambuco, 76 (31,79\%). Quanto aos cursos concentrados na área de formação tecnológica, o estado do Maranhão dispõe de dois (0,58\%); o Piauí contém 18 (5,24\%); no estado paraibano há 32 (9,32\%); em Alagoas, 19 (5,53\%); no Ceará estão localizados 86 (25,7\%); na Bahia, encontram-se 81 (23,03\%); no Rio Grande do Norte são apenas 15 (4,37\%); em Pernambuco, 90 (26,23\%). No limite, há apenas um curso de ciências humanas no Maranhão (1,13\%); no Piauí são oito (9,09\%); na Paraíba, três (3,40\%); Alagoas oferta 13 (14,77\%); no Ceará são 14 (15,90\%); na Bahia, 25 (28,40\%); no Rio Grande do Norte, concentram-se sete (7,95\%); e, por fim, no estado pernambucano, encontram-se apenas 17 (19,36\%).

No panorama exposto pelo Gráfico 3, assim como pelo Gráfico 2, se somada a quantidade total de cursos, evidenciamos a predominância da oferta de cursos da área tecnológica, seguida da engenharia, e, por conseguinte, da saúde, o que consequentemente aponta a subalternização dos cursos de ciências humanas, conforme os dados da Região Nordeste. Em acréscimo, é nítido o quantitativo superior de oferta de cursos por parte dos centros universitários em comparação com as universidades. $\mathrm{Na}$ Tabela 1, mostramos esse contexto com precisão.

\section{Tabela 1 - Oferta de cursos de graduação por área de formação das Instituições Privadas de Ensino Superior (IPES) do Nordeste: universidades e centros universitário, 2018.}

\begin{tabular}{c|c|c|c|c}
\hline \multirow{2}{*}{$\begin{array}{c}\text { Área de } \\
\text { formação }\end{array}$} & $\begin{array}{c}\text { Universidades } \\
\text { (absoluto) }\end{array}$ & $\begin{array}{c}\% \\
\text { (variável) }\end{array}$ & $\begin{array}{c}\text { Cursos por tipo de instituição } \\
\text { universitários } \\
\text { (absoluto) }\end{array}$ & $\begin{array}{c}\% \\
\text { (variável) }\end{array}$ \\
\hline Saúde & 47 & 15,46 & 257 & 84,54 \\
\hline Tecnológica & 68 & 16,54 & 343 & 83,46 \\
\hline Engenharia & 97 & 28,86 & 239 & 71,14 \\
\hline $\begin{array}{c}\text { Formação de } \\
\text { professores }\end{array}$ & 34 & 27,86 & 88 & 72,14 \\
\hline Total & 246 & 20,97 & 927 & 79,03 \\
\hline
\end{tabular}

Fonte: e-MEC (2018).

Com base nos dados coletados, constatamos que há predominância na oferta de cursos por parte dos centros universitários da ordem de 79,03\%, além de essa superioridade ser em todas as áreas de formação. Isso pode estar rela- 
cionado com a menor responsabilidade dessas instituições no desenvolvimento de pesquisa, algo que é mais concentrado em universidades, com destaque às privadas. No que diz respeito aos cursos da área tecnológica, eles são a grande maioria, representando a taxa percentual de $35,03 \%$ do total de cursos, sendo $16,54 \%$ em universidades e $83,46 \%$ em centros universitários. A segunda maior oferta é dos cursos concentrados nas áreas de engenharia $(28,64 \%)$, dos quais $28,86 \%$ estão localizados em universidades e $71,14 \%$ em centros universitários. No que concerne aos cursos da área da saúde, estes representam oferta percentual de 25,91\% nessas IPES: 15,46\% dos cursos são ofertados por universidades e $84,54 \%$ estão nos centros universitários. Os cursos de ciências humanas possuem a menor oferta nas IPES nordestinas em análise, apenas 10,40\% do total. Desse valor, $27,86 \%$ dos cursos são ofertados nas universidades e $78,14 \%$ em centros universitários.

Não obstante se tratarem de IPES, as universidades parecem mais discretas no quantitativo, bem como na diversificação da oferta de cursos. Por outro lado, os centros universitários destacam as áreas de formação prioritariamente em sua oferta. De todo modo, o cenário das IPES na Região Nordeste brasileira segue as orientações do BM.

\section{DIVISÃO INTERNACIONAL DO CONHECIMENTO E SUBALTERNIZAÇÃO DAS CIÊNCIAS HUMANAS}

$\mathrm{Na}$ ascensão da lógica da economia do conhecimento, as instituições educacionais vão sofrendo metamorfoses decorrentes da lógica da financeirização da economia (Afonso, 2015). Esse fenômeno propicia elementos que suplementam a construção hierárquica do conhecimento e, consequentemente, condicionam as IES. Nessa acepção, com os dados coletados nas IPES do Nordeste brasileiro, percebemos a efetivação dessa lógica, sobretudo na predominância da oferta de cursos de formação profissional no nível de graduação, correspondendo às orientações das agências internacionais.

Para Afonso (2015), há a subalternização das ciências humanas, de maneira especial das ciências da educação, em virtude da não monopolização do conhecimento produzido, em que o mercado de patentes está na ordem do dia nas ciências duras. Conforme o autor, levando em conta

o contexto do capitalismo cognitivo, que invade lentamente as instituições de ensino superior [...], a explicação [...] pode ser a de que a referida subalternização ou desvalorização tem a ver com o facto de as ciências sociais e humanas [...] não adotarem estratégias de fechamento (ou de preservação de monopólio) relativamente ao conhecimento que produzem, distinguindo-se assim de outras ciências em que o valor do conhecimento mercadorizável está fortemente dependente da "capacidade de monopolizar o direto de se servir dele" [...].É também isso que está em causa quando, mais genericamente, se fala da desvantagem das ciências sociais e humanas face às outras ciências. (Afonso, 2015, p. 281-282) 
Para se aproximar mais precisamente do fenômeno da hierarquização das áreas do conhecimento, é preciso lançar olhos para a lógica da DIT e suas reverberações na concepção de mercadoria, conhecimento e formação profissional. Nesse sentido, consoante Pochmann (2000), são duas concepções que dão conta de analisar os fenômenos decorrentes da DIT. A primeira diz respeito à ideia das vantagens comparativas que alguns Estados nacionais possuem na produção e exportação de seus produtos e serviços.

Essa concepção compreende que o predomínio de algumas nações sobre as demais se limita estritamente à esfera econômica. Ainda, que o crescente processo de importação e exportação de produtos e serviços torna exequível a redução das assimetrias envolvendo os estágios do desenvolvimento econômico. Com isso, Pochmann $(2000$, p. 3) assevera que "a integração no sistema econômico mundial, por ser realizada através da maior competição entre nações, seria capaz de gerar saldos positivos entre a destruição e a criação de postos de trabalho para as áreas geográficas mundiais com vantagens comparativas". Com efeito, o eixo gravitacional do livre comércio global dá-se pela especialização das cadeias produtivas. Essa concepção conta com o apoio das agências internacionais por meio da publicação de documentos que orientam a expansão nacional articulada com sua integração com o mercado global. "A desregulamentação dos mercados financeiros, de produtos e do trabalho constitui peça fundamental no roteiro de medidas necessárias para o melhor acesso ao desenvolvimento econômico e à ampliação dos postos de trabalho"(Pochmann, 2000, p. 3).

A segunda concepção posiciona-se contrariamente à primeira e descarta a ideia de vantagens comparativas, pois identifica a constituição de uma hierarquização da economia global própria da operacionalização do sistema sociometabólico global de capital. Ainda com Pochmann (2000), o autor considera que, pela correlação de forças que envolve os diversos Estados nacionais, se tornou factível a criação de um espaço geográfico em escala mundial para a "geração e absorção de riqueza e de criação e destruição de postos de trabalho, havendo possibilidades de manifestação de múltiplas formas de dominação de uma nação por outra, através da dimensão política, militar, econômica e cultural" (Pochmann, 2000, p. 4).

Com efeito, as duas concepções contribuem em nossa argumentação na criação de um espaço global em que condicionalidades são canalizadas dos Estados nacionais centrais para as nações periféricas, visto que as particularidades da produção e comercialização de seus serviços constituem um processo de estratificação e assimetria entre as nações. Nessa acepção, a ascensão da economia do conhecimento, mediante a noção de gestão da produção do conhecimento, assume centralidade na competitividade econômica e empresarial de um Estado nacional. Para Drucker (2007, p. 201),

A produtividade do conhecimento será um fator determinante na posição competitiva de uma indústria, de uma empresa e de um país inteiro. Nenhum país, indústria ou empresa apresenta qualquer vantagem ou desvantagem natural. A única que pode ter é a capacidade para explorar o conhecimento universal disponível. A única coisa que será mais importante, quer na economia nacional quer na internacional, é o desempenho da gestão no sentido de tornar o conhecimento produtivo. 
Para as agências internacionais, o conhecimento produtivo para as nações periféricas, de maneira especial para o Brasil, conforme foi exposto com base no documento do BM, deve habilitar a formação técnica fundamentada em elementos tecnológicos. Com isso, as áreas que ganham destaque, nesse contexto, são as engenharias e os cursos de áreas tecnológicas. Todavia, o movimento particular da economia periférica brasileira evidencia a ascensão dos postos de trabalho no setor de serviços, sobretudo na saúde. Assim, essa área ganha ênfase pelos empresários da educação superior.

Com a apresentação dos dados das IPES localizadas no Nordeste, é possível alegar que no setor privado a oferta de cursos de formação profissional, no nível de graduação, segue as orientações do mercado mundial. A predominância na oferta de cursos centrados na área tecnológica é evidente. Todavia, esse processo está articulado ao movimento de internacionalização da educação superior. De acordo com Azevedo e Catani (2013, p. 285),

a internacionalização da educação superior e a circulação de ideias para além das fronteiras nacionais são calcadas, esquematicamente, em dois princípios contraditórios: a solidariedade internacional e a concorrência em um mercado global de educação e conhecimento. Essas duas expressões são como oximoros, isso é, um termo silencia o outro. Em geral, quando essas expressões aparecem ao mesmo tempo em uma política de internacionalização é devido à força de retórica.

A ênfase dada às ciências duras decorre da noção de concorrência e produtividade para um sistema econômico que vivencia crises em todos os seus setores. É lícito ressaltar a necessidade do movimento duplo: primeiramente, a importância dada no setor educacional, especialmente da educação superior por parte do setor empresarial articulado aos setores financeiros, que compreendem isso como educação-mercadoria; por outro lado, a vinculação com o mercado, além das condicionalidades das nações hegemônicas, implica a relevância dada à formação profissional para setores com rentabilidade necessária para áreas estratégicas para a particularidade capitalista dependente brasileira. Assim, a ênfase nesse momento é dada aos insumos, ou seja, aos meios, atendendo aos anseios dos setores industriais e de serviços na formação dos profissionais necessários. Esse movimento é caracterizado por mercadoria-educação (Rodrigues, 2007).

A mercadoria-educação, articulada à concepção dos setores produtivos para o sistema econômico, condiciona a ação das IPES aos interesses dos setores estratégicos do capitalismo periférico, isto é, cursos centrados na área tecnológica em detrimento dos cursos de humanidades, que, em contrapartida, buscam a sólida formação teórica em que reflexão, crítica e posicionamento tendo em vista sua interface com a realidade social concreta são a base. Esse processo constitui, portanto, uma hierarquia entre as áreas de formação: as que possuem mais rentabilidade para o mercado ganham destaque na criação e oferta de cursos pelas IPES.

Essa hierarquização evidencia a subalternização das ciências humanas. Esse processo é suplementado com o posicionamento contrário de correntes político- 
-ideológicas ao pensamento crítico acerca do mundo decorrente da formação na área das humanidades. Afonso (2015) contextualiza o cenário português por meio da contenção das ciências humanas em função do neoliberalismo:

No que diz respeito a Portugal, por exemplo, as ciências sociais e humanas [tiveram] um grande impulso e uma significativa demanda ao nível da educação superior, para os quais muito contribuiu a legitimidade conquistada face a outras ciências na sequência da transição do regime autoritário para o democrático. Porém, na conjuntura atual, marcada pela radicalização de agendas neoliberais e neoconservadoras, as decisões de política pública são fortemente adversas à continuidade do apoio às ciências sociais e humanas e, em particular, às ciências da educação (sobretudo as que adotam perspectivas mais reflexivas e problematizadoras). (Afonso, 2015, p. 282)

Esse processo de subalternização das ciências humanas engendra severas implicações, até mesmo no processo de formação de professores, com redução de oferta de cursos de licenciatura em prol da oferta de bacharelados ${ }^{10}$. Nesse itinerário analítico, o cenário de formação de profissional vinculado às ciências humanas parece estar perdendo espaço no mercado, e a lógica da criação de reserva de mercado recai para as áreas tidas como nichos de alta rentabilidade para o capitalismo periférico (tecnologia, engenharia e saúde).

No limite, fica explícito que a preocupação recai sobre a exploração da educação superior e sua decorrente privatização - não é à toa que, consoante Paula, Costa e Lima (2017), o setor das IPES representa 87,71\% da quantidade de IES no Brasil, além de também concentrarem o maior quantitativo de matrículas discentes, $78,25 \%$ - bem como sobre a formação profissional ideal para o mercado, atendendo, dessa forma, o movimento maior das diretrizes globais para as políticas educacionais. Esse panorama está calcado naquilo que Ball (2001) chama de paradigma de governo educacional. Nesse contexto, Dolowitz et al. (2000) compreendem esse fenômeno como convergência de políticas ou transferência de políticas. De todo modo, essas concepções convergem quando o assunto diz respeito à sujeição da educação às "prescrições e assunções normativas do economicismo e o tipo de cultura na qual a escola existe e pode existir" (Lingard, Ladwing e Luke, 1998, p. 84).

É lícito ressalvar que as mutações nos sistemas de emprego podem estar condicionando a demanda por cursos superiores, ou seja, de formação profissional, influenciando, assim, as mudanças nas ofertas por parte dos setores privados da educação superior. No limite, esse processo dá relevo às áreas pertinentes às ciências duras em detrimento das humanas, decorrendo, com isso, na sua subalternização.

10 O Censo da Educação Superior (Inep, 2016) evidencia que em 2016 foram efetivadas no Brasil 1.520.494 matrículas discentes em licenciaturas, enquanto no bacharelado foram 5.549 .736 matrículas. 


\section{À GUISA DE CONCLUSÃO}

A educação superior no Brasil vivencia metamorfoses advindas das orientações das agências internacionais, sobretudo do BM. Esse processo engendrou implicações que evidenciam a predominância do setor privado nesse nível de ensino, bem como a prevalência da oferta de cursos superiores de formação profissional das ciências duras em comparação com os das ciências humanas no Nordeste brasileiro.

Esse processo está articulado com a ascensão da economia do conhecimento, que prioriza a produção de conhecimentos fechados e exatos e sua alta capacidade de comercialização, por meio do sistema de patenteamento. Em contrapartida, os cursos de ciências humanas têm dificuldade de fechar suas conclusões acerca dos objetos em análise em função de os complexos sociais não serem fechados e estarem em contínuo movimento, atrapalhando sua inserção no sistema de patentes. Ainda, a própria lógica do mercado condiciona esse panorama, com as alterações nos postos de emprego, que resultam em modificações na oferta de cursos por parte das IPES, além de atender a um interesse advindo dos empresários dos setores industriais e de serviços.

Com a subalternização das ciências humanas, alguns questionamentos surgem no bojo desse contexto: em que ponto as ciências humanas não contribuem para a rentabilidade do sistema econômico como as demais áreas das ciências duras? As ciências humanas concentram uma grande variedade de cursos de licenciatura, isto é, de formação de professores. Com sua subalternização e decorrente redução de oferta, onde ficará localizada a oferta de licenciatura? Esses problemas necessitam ser investigados e debatidos para que possam ser traçadas estratégias para se opor a esse movimento crescente na educação superior das nações periféricas.

O campo das ciências humanas deve ser posto na ordem do dia, ser debatido pelos atores que o constituem no cotidiano de seu campo acadêmico e profissional. Para Bourdieu (2004, p. 22-23), no tratamento de sua teoria dos campos, "todo campo, como o campo científico [...] é um campo de forças e um campo de lutas para conservar ou transformar este mesmo campo de forças". Portanto, é crucial a ação dos sujeitos que compõem o campo das ciências humanas e que seja intensificada a correlação de forças político-ideológicas, opondo-se à expansão da economia baseada no conhecimento, pois o movimento da comodificação implica metamorfoses na própria natureza do conhecimento.

\section{REFERÊNCIAS}

AFONSO, A.J. A educação superior na economia do conhecimento, a subalternização das ciências sociais e humanas e a formação de professores. Avaliação, Campinas, v. 20, n.2, p. 269-291, 2015. Disponível em: http://www.scielo.br/scielo.php?pid=S141440772015000200269\&script=sci_abstract\&tlng=pt. Acesso em: 9 jun. 2018. http://dx.doi.org/10.590/S1414-40772015000200002

AZEVEDO, M. L. N.; CATANI, A. M. Educação superior, internacionalização e circulação de idéias: ajustando os termos e desfazendo mitos. Inter-ação, v. 38, n. 2, p. 273-291, 2013. Disponível em: https://www.revistas.ufg.br/interacao/article/ view/26103. Acesso em: 29 ago. 2019. https://doi.org/10.5216/ia.v38i2.26103 
BALL, S. J. Diretrizes políticas globais e relações políticas locais em educação. Currículo sem Fronteiras, v. 1, n. 2, p. 99-116, 2001. Disponível em: http://www. curriculosemfronteiras.org/vol1iss2articles/ball.pdf. Acesso em: 2 mar. 2018.

BANCO MUNDIAL. Conhecimento e inovação para a competitividade. Brasília: Confederação Nacional da Indústria, 2008.

BARRETO, R. G.; LEHER, R. Do discurso e das condicionalidades do Banco Mundial, a educação superior "emerge" terciária. Revista Brasileira de Educação, v. 13, n. 39, p. 423-436, 2008. Disponível em: http://www.scielo.br/pdf/rbedu/v13n39/02.pdf. Acesso em: 4 jun. 2019. http://dx.doi.org/10.1590/S1413-24782008000300002

BELL, D. The coming of post-industrial society. Nova York: Basic Books, 2001.

BOURDIEU, P. Os usos sociais da ciência. Por uma sociologia clínica do campo científico. São Paulo: EdUNESP, 2004.

CHESNAIS, F. A mundialização do capital. São Paulo: Xamã, 1996.

DOLOWITZ, D. P. et al. Policy Transfer and British Social Policy: Learning from the USA? Buckingham: Open University Press, 2000.

DRUCKER, P. Sociedade pós-capitalista. Lisboa: Actual, 2007.

DUARTE, N. Sociedade do conhecimento ou sociedade das ilusões?: quatro ensaios crítico-dialéticos em filosofia da educação. Campinas: Autores Associados, 2008.

E-MEC. Instituições de educação superior e cursos cadastrados. e-MEC, 2018. Disponível em: http://emec.mec.gov.br/. Acesso em: 13 jun. 2018.

FONSECA, J. J. S. Metodologia da pesquisa científica. Fortaleza: UEC, 2002.

IANNI, O. Teorias da globalização. Rio de Janeiro: Civilização Brasileira, 1997.

INSTITUTO BRASILEIRO DE GEOGRAFIA E ESTATÍSTICA (IBGE). Síntese de indicadores sociais: uma análise das condições de vida da população brasileira 2017. Rio de Janeiro: IBGE, 2017. Disponível em: https://biblioteca.ibge.gov.br/visualizacao/ livros/liv101459.pdf. Acesso em: 11 jun. 2018.

INSTITUTO NACIONAL DE ESTUDOS E PESQUISAS EDUCACIONAIS ANÍSIO TEIXEIRA (INEP). Censo da Educação Superior 2016. Brasília: INEP, 2016. Disponível em: http://download.inep.gov.br/educacao_superior/censo_superior/ documentos/2016/notas_sobre_o_censo_da_educacao_superior_2016.pdf. Acesso em: 18 maio 2018.

JARVIS, P. Globalização e mercado da aprendizagem. In: LIMA, L. C. (org.). Educação de adultos. Fórum III. Braga: Universidade do Minho/UEA, 2000. p. 29-41.

KURZ, R. The substance of capital. Londres: Chronos publications, 2016.

LINGARD, B.; LADWING, J.; LUKE, A. School effects in postmodern conditions. In: SLEE, R.; WEINERM, G.; TOMLINSONM S. (orgs.). School effectiveness for whom? Challenges to the school effectiveness and school improvement movements. Londres: Falmer, 1998. p. 73-89.

LINGARD, B.; RIZVI, F. Globalisation and the Fear of Homogenisation in Education. In: BALL, S. J. (org.). Sociology of Education: Major Themes. Londres: Routledge/ Falmer, 2000. p. 2.091-2.117. 
LÜDKE, M.; ANDRÉ, M. E. D. A. Pesquisa em educação: abordagens qualitativas. São Paulo: EPU, 1986.

MINAYO, M. C. S. (org.). Pesquisa social: teoria, método e criatividade. Petrópolis: Vozes, 2001.

MORAES, R. Análise de conteúdo. Revista Educação, Porto Alegre, v. 22, n. 37, p. 7-32, 1999. Disponível em: http://cliente.argo.com.br/ mgos/analise_de_conteudo_moraes. html. Acesso em: 5 jun. 2019.

OLSSEN, M.; PETERS, M. A. Neoliberalism, higher education ant the knowledge economy: from the free Market to knowledge capitalism. Journal of Education Policy, Londres, v. 20, n. 3, p. 313-345, 2005. https://doi.org/10.1080/02680930500108718

ORGANIZAÇÃO DAS NAÇÕES UNIDAS PARA A EDUCAÇÃO, A CIÊNCIA E A CULTURA (UNESCO). Rumo às sociedades do conhecimento. Lisboa: Instituto Piaget, 2017.

PAULA, A. S. N. de; COSTA, F. J. F.; LIMA, K. R. R. A condicionalidade do estado avaliador e suas implicações na avaliação e a expansão mercantilizada da educação superior brasileira. Revista Internacional de Educação Superior, Campinas, v. 4, n. 2, p. 330-346, 2017. Disponível em: https://periodicos.sbu.unicamp.br/ojs/index.php/ riesup/article/view/8650708/17649. Acesso em: 13 jun. 2018. https://doi.org/10.20396/ riesup.v4i2.8650708

POCHMANN, M. Economia global e a nova Divisão Internacional do Trabalho. Campinas: IE/Unicamp, 2000.

RHOADES, G.; SLAUGHTER, S. O capitalismo académico na nova economia: escolhas e desafios. In: PARASKEVA, J. (org.). Capitalismo académico. Mangualde: Edições Pedago, 2009. p. 7-36.

RIKOWSKI, G. Privatisation in education and commodity forms. Journal for Critical Education Policy Studies, v. 15, n. 3, p. 29-56, 2017. Disponível em: http://www.jceps. com/archives/3620. Acesso em: 6 jun. 2018.

RODRIGUES, J. Os empresários e a educação superior. Campinas: Autores Associados, 2007.

ROTHEN, J. C. et al. Concepções de qualidade nos documentos oficiais sobre a educação superior. Comunicações, Piracicaba, v. 26, n. 1, p. 5-26, 2019. Disponível em: https://www.metodista.br/revistas/revistas-unimep/index.php/comunicacoes/ article/view/3496. Acesso em: 5 jun. 2019. http://dx.doi.org/10.15600/2238-121X/ comunicacoes.v26n1p5-26

SANTIAGO, R.; CARVALHO, T. Mudança no conhecimento e na profissão acadêmica em Portugal. Cadernos de Pesquisa, São Paulo, v. 41, n. 143, p. 402-426, 2011. http://dx.doi.org/10.1590/S0100-15742011000200005

SER EDUCACIONAL. O setor de educação no Brasil: visão geral do setor de ensino superior. 2018. Disponível em: http://ri.sereducacional.com/sereducacional/web/ conteudo_pt.asp?idioma=0\&conta=28\&tipo=47925. Acesso em: 5 jun. 2019.

SGUISSARDI, V. Estudo diagnóstico da política de expansão da (e acesso à) educação superior no Brasil: 2002-2012. Piracicaba: 2015. (mimeo.) 
SRNICEK, N.; WILLIAMS, A. Inventing the future: postcapitalism and a world without work. Londres: Veso, 2015.

VERGER, A.; STEINER-KHAMSI, G.; LUBIENSKI, C. The emerging global education industry: analysing market-making in education through market sociology. Globalisation, Societies and Education, v. 15, n. 3, p. 325-340, 2017. https://doi.org /10.1080/14767724.2017.1330141

\section{SOBRE OS AUTORES}

Alisson Slider do Nascimento de Paula é doutor em educação pela Universidade Estadual do Ceará (UECE). Professor do Centro Universitário INTA (UNINTA).

E-mail: alisson.slider@yahoo.com

Frederico Jorge Ferreira Costa é doutor em educação pela Universidade Federal do Ceará (UFC). Professor da Universidade Estadual do Ceará (UECE).

E-mail: frederico@uece.br

Kátia Regina Rodrigues Lima é doutora em educação pela Universidade Federal de São Carlos (UFSCar). Professora da Universidade Regional do Cariri (URCA).

E-mail: kareli2004@yahoo.com

Recebido em 14 de junho de 2018

Aprovado em 7 de junbo de 2019 